\title{
Nota sobre la procedencia de los manuscritos hebreos del monasterio de San Martín de Madrid
}

\author{
Concha Varela-Orol* \\ Universidade da Coruña \\ ORCID 0000-0002-6769-8349
}

Se presenta la edición de un texto inédito de Martín Sarmiento que permite conocer la procedencia de los manuscritos hebreos de la Biblioteca del Monasterio de San Martín de Madrid, en parte hoy en la Biblioteca Nacional de España.

Palabras clave: María Guadalupe de Lencastre y Cárdenas, Duquesa de Aveiro; José Sáenz de Aguirre; Martín Sarmiento.

Note on the Origin of the Hebrew Manuscripts from Monastery of San Martín in MADRID.- We present the edition of an unpublished text by Martín Sarmiento that allows us to know the origin of the Hebrew manuscripts from the Library of Monastery of San Martín in Madrid, partly today in Biblioteca Nacional de España.

Keywords: María Guadalupe de Lencastre y Cárdenas, Duchess of Aveiro; José Sáenz de Aguirre; Martín Sarmiento.

Como es conocido, una parte de los manuscritos hebreos de la Biblioteca Nacional proceden del monasterio de San Martín de Madrid. Su llegada a la casa benedictina se ha puesto en relación con Martín Sarmiento, que habría conseguido reunir tan importante colección ${ }^{1}$, y también se ha

* concepción.varela@udc.gal

${ }^{1} \mathrm{M}^{\mathrm{a}}$ T. ORTega Monasterio, «Las bibliotecas y sus manuscritos hebreos», en Catálogo de manuscritos hebreos de la Comunidad de Madrid, ed. F. J. DEL BARCO DEL BARCO. Vol. 2 (Madrid 2004) págs. 19-54: 35.

Copyright: (C) 2017 CSIC. Este es un artículo de acceso abierto distribuido bajo los términos de una licencia de uso y distribución Creative Commons Attribution (CC-by) España 3.0. 
supuesto que procedían de la biblioteca del Duque de Medinasidonia ${ }^{2}$, cuyo vínculo con San Martín de Madrid y con el propio Sarmiento es bien conocido. El objeto de esta nota es editar un texto de Martín Sarmiento que nos permite fijar otra procedencia para estos manuscritos llegados a la casa benedictina antes de haber nacido el autor, aunque efectivamente sea él quien nos ofrece la información, como había hecho con otras noticias referidas a alguno de estos códices, cotejándolos con los textos impresos ${ }^{3}$, o bien redactando apuntes sobre su contenido para acompañar el manuscrito 4 .

Desde muy joven el benedictino parece haber prestado atención a las culturas orientales, ya que en el Catálogo de los pliegos ${ }^{5}$ dice que entre 1715 y 1718, con apenas 20 años, copió los alfabetos orientales de Teseo Ambrogio en la biblioteca del Colegio de San Vicente de Salamanca, y en 1718 extractó la Bibliotheca Magna Rabinica de Giulio Bartoloccio.

El interés de Sarmiento por los estudios semíticos es patente también en su biblioteca. En su colección de Biblias, que constituyen cincuenta y siete registros de su Catálogo $^{6}$, veinticinco tienen el texto hebreo, a las que se añaden ediciones parciales de sus libros (Salmos, Pentateuco). Entre las obras incluidas en el apartado de Concordancias de su biblioteca solo un número menor carecían del texto hebreo, y las fuentes hebreas vuelven a ser sobresalientes en otras secciones de su catálogo, como Aparato, Crítica y Erudición de la Escritura, o en Erudición oriental, donde destacan un conjunto de gramáticas hebreas (Roberto Belarmino, Lodewijk de Dieu, Edward Slaughter, Francisco Masclef, Martín del Castillo) y las colecciones de la familia Buxtorf y de Johann Heinrich Hottinger, Adrian

${ }^{2}$ G. DE ANDRÉs, «Una valiosa colección de códices del convento benedictino de San Martín de Madrid», Anales del Instituto de Estudios Madrileños 30 (1991) págs. 252-253.

${ }^{3}$ Ortega Monasterio, «Las bibliotecas y sus manuscritos hebreos», págs. 35-36.

${ }^{4}$ Además de las notas que adjuntó a los manuscritos de San Martín, como indica en el texto transcripto, conocemos otra que redacta para un rollo en pergamino de la Biblioteca Real, conteniendo fragmentos del Éxodo. Museo de Pontevedra [en adelante, MP], Col. Medinasidonia, t. II, fols. 397-398.

5 J. Santos Puerto, ed., «Una bio-bibliografía actualizada de Martín Sarmiento. Catálogo de los pliegos (...) sobre diferentes asuntos», Sarmiento 6 (2002) págs. 69-95.

${ }^{6}$ M. SARmiento, Catálogo de los Autores de quienes yo fr. Martín Sarmiento Benedictino tengo ad usum, ó todas sus obras, ó parte de ellas. ó algún tomo suelto, y separado ... (174?-176?). Real Academia de la Historia (Madrid), Ms. 9/1829. 
Reland y John Selden. Las referencias a estos libros no faltarán a lo largo de su obra, como puede comprobarse en las Memorias para la Historia de la poesía, y en sus trabajos sobre los alfabetos, a partir de las obras ya citadas y de otras que figuran en su biblioteca. Estos trabajos se plasmaron en su escrito Pangrammaticon Lexicon", redactando «en quadernos en $4^{\circ}$ todos los alphabetos que he podido recoger, asta hoy $1^{\circ}$ de enero de 1767; desde 1718» ${ }^{8}$.

Los textos en hebreo no eran para Sarmiento un tema menor, ya que cree que la lengua hebrea es la primitiva y «bastante» conectada con las lenguas actuales ${ }^{9}$. Muestra de su interés filológico son las anotaciones hechas en el catálogo de la biblioteca de la Catedral de Toledo en $1726^{10}$, donde al describir los manuscritos bíblicos, hebreos o no, indicará cuando incluyen vocabulario de voces hebreas. Sin fecha, extractará un vocabulario de castellano antiguo extraído de la Biblia de Ferrara, en el que indica «Voy leyéndola toda...para hacer mas idea de las voces hebreas... y para penetrar algunas etymologias, y primitivas significaciones de algunas voces castellanas» ${ }^{11}$.

También conocemos su participación en el proyecto de Benjamin Kennicott sobre la colación de las Biblias hebreas anteriores a la invención de la imprenta $^{12}$. En 1764 en carta a Rodríguez Campomanes ${ }^{13}$ le

\footnotetext{
${ }^{7}$ M. SARmiento, Pangrammaticon Lexicon, sive Clavis Omnium Alphabetorum Novoveterum. (1718-1767). Archivo General de la Fundación Casa Medina Sidonia (Sanlúcar de Barrameda, Cádiz [en adelante AGFCMS]), Col. Medinasidonia, t. I, fols. 47-64: 47.

${ }^{8}$ J. SAntos Puerto, ed., «Una bio-bibliografía actualizada», pág. 74.

${ }^{9}$ M. Sarmiento, Memorias para la historia de la Poesía y Poetas españoles ... (Madrid 1775) págs. 9 y 12.

${ }^{10}$ M. SARmiento, Bibliotheca de la Santa Yglesia de Toledo. Borrador de los Libros que en ella registré el año de 1727. AGFCMS, Col. Medinasidonia, t. IV, fols. 27-73.

${ }^{11}$ M. SARmiento, Biblia Ferrariense en castellano antiguo traducida (s.a.). MP, Col. Medinasidonia, t. II, fols. 161-214: 161v.

12 B. Kennicott, Vetus Testamentum Hebraicum cum variis lectionibus (Oxonii 1776-1780).

${ }^{13}$ M. SARmiento, Carta a Campomanes sobre la recopilación de textos hebreos manuscritos en España..., 8 de marzo de 1764. Archivo Campomanes (Fundación Universitaria Española [Madrid]), Ms. 48-124. El texto ha sido editado en J. Simón DíAz, «El P. Sarmiento en los archivos de Campomanes y de Silos: seis cartas más», Cuadernos de Estudios Gallegos 27 (1972) págs. 306-321.
} 
pide su intervención para traer a Madrid a la persona que pueda realizar la colación de un manuscrito hebreo del monasterio de San Martín. La carta a Campomanes explica brevemente el proyecto de Kennicott, del que le supone conocedor, y, como tantas veces en sus textos, reivindica el papel de su orden en este tipo de trabajos, citando la obra del maurino Pierre Sabatier sobre las versiones latinas de la Biblia, obra en la que considera que se inspiró Kennicott.

Por esta carta sabemos que fue el diplomático británico Lewis de Visme, al que hace referencia en el texto que transcribimos, quien visitó el monasterio para ver «un grande códice manuscrito Hebreo, que contiene la mitad de la Biblia ...; además de ser muy corpulento, todo es de Pergamino, con unos caracteres Hebreos, quadrados, hermosos, y muy grandes. Y todo el texto está cargado de los Puntos Masoréticos; y de los Acentos Músicos». Visme quiere que el texto sea colacionado, y con esta finalidad pide Sarmiento a Campomanes que traiga a Madrid a Pedro Carbonel, que había participado en la tertulia del benedictino y había sido profesor de griego del fiscal del Consejo de Castilla.

Porque además del interés filológico señalado, hay en Sarmiento una reivindicación de las culturas hebrea y árabe como configuradoras de nuestra historia, para cuya reconstrucción es preciso recuperar manuscritos árabes y hebreos existentes en los archivos y bibliotecas españolas, y adquirirlos en Oriente ${ }^{14}$. En la carta a Campomanes señalada insistirá en la importancia de los códices hebreos existentes en España porque «Los hombres más Doctos entre los hebreos, excepto Salomon Jarchi Provenzal; todos han sido españoles, y Los mas Antiguos desde el siglo $12^{\circ}$ asta el $16^{\circ}$. Esto lo confiesan todos los Hebreos de hoy», y por supuesto «Bien quisiese que en la obra de Kenincott, hiziese España algún Papel» ${ }^{15}$.

Pues bien, no es de extrañar que el benedictino nos dejase alguna información más sobre los códices hebreos existentes en su monasterio ya en el momento en que entra de novicio (1710). El texto aquí transcripto forma parte de la Obra de los 660 pliegos, una obra que el benedictino dice redactar entre 1762 y 1766, y está incluido en el marco de un escrito

${ }^{14}$ M. SARmiento, Sobre los códices orientales de la Real Biblioteca del Escorial (1750) AGFCMS, Col. Medinasidonia, t. VI, fols. 53-92: 56.

${ }^{15}$ Sarmiento, Carta a Campomanes, fols. 2-3. 
sobre las falsificaciones de Miguel de Luna, como ejemplo de la utilización de caracteres hebreos en otras lenguas.

El texto que transcribimos señala que había sido el también benedictino José Sáenz de Aguirre quien legó estos manuscritos a su monasterio, en su viaje de Salamanca a Roma. Antes de irse a esta ciudad Aguirre está en Madrid residiendo en el monasterio de San Martín, y conoce a María Guadalupe de Lencastre y Cárdenas, duquesa de Aveiro, quien le regala «unos» dieciocho manuscritos hebreos, que el cardenal lega a la biblioteca del monasterio ${ }^{16}$. Así podemos datar la llegada de los manuscritos alrededor de los años 1686, año en que Aguirre había sido nombrado cardenal, y 1687, ya que a mediados de este año está en Roma.

La duquesa de Aveiro (Azeitão 1630-Madrid 1715), también duquesa de Maqueda y Arcos, fue una mujer excepcional, conocedora de muchas lenguas, entre ellas el hebreo ${ }^{17}$, y cuyo conocimiento, más allá de la Península Ibérica, parece haber sido notable, como indican los numerosos impresos publicados con ocasión de su muerte ${ }^{18}$. Su papel en los círculos eruditos y de la alta sociedad queda bien expresado en las palabras de Saint-Simon: «Sa maison à Madrid étoit le rendez-vous journalier de tout ce qu'il y avoit de plus considérable en esprit, en savoir et en naissance...».

La duquesa mantuvo un alto compromiso con la iglesia católica a través de sus aportaciones a la labor de los misioneros en América y Asia ${ }^{19}$, lo que le valdrá el calificativo de Madre de las misiones, a los que habría que añadir sus donaciones de cuadros y otros objetos artísticos a iglesias

${ }^{16}$ Los manuscritos hebreos que figuran en el Índice de 1770 de la Biblioteca del monasterio de San Martín (DE ANDRÉs, «Una valiosa colección de códices») son efectivamente 18, aunque en 1751 Sarmiento hace referencia a 19 (OrTEgA MonASTERIO, «Las bibliotecas y sus manuscritos hebreos», pág. 35). De ellos se han identificado en la actualidad 7 manuscritos en la Biblioteca Nacional de Madrid.

${ }^{17}$ Duc de Saint-Simon, Louis de Rouvroy, Mémoires du Duc de Saint-Simon... Tome Second (Paris 1873) pág. 459.

${ }^{18}$ G. A. Thomas, «The Death of the Duchess of Aveiro: The Life and Legacy of María de Guadalupe de Lencastre», Dieciocho: Hispanic Enlightenment 39:1 (2016) págs. 29-42.

${ }^{19}$ M. A. Ramos SuÁrez, «Doña María Guadalupe de Lancaster, duquesa de Aveiro, y su devoción a los mártires del Japón», en Japón y Occidente: El patrimonio cultural como punto de encuentro, ed. A. GómEz Aragón (Sevilla 2016) págs. 543-553. 
y monasterios. Sarmiento la define como «doctísima y muy erudita señora». Su cultura es patente en el inventario post mortem de su biblioteca, que fue depositada por su hijo en el convento franciscano de Santa Eulalia de Marchena ${ }^{20}$, pero que finalmente debió de ser trasladada al palacio de los duques de Arcos de esta ciudad donde finalmente fue comprada por el librero madrileño Francisco Manuel de Mena, que la vendió al menudeo ${ }^{21}$. Cómo habían llegado estos manuscritos hebreos a manos de la duquesa no lo sabemos. Es conocido que al menos dos de estos manuscritos, hoy en la Biblioteca Nacional, proceden de Alcalá de Henares ${ }^{22}$. Sobre los restantes no pueden descartarse algunas hipótesis. En primer lugar, algunos podrían haber llegado de Portugal, donde las comunidades judías tenían fuerte presencia, también en Aveiro, e incluso de la propia biblioteca del Palacio ducal de Azeitão, que acabaría ardiendo a causa del terremoto de $1755^{23}$. Pero tampoco es descartable, dada la fuerte relación que la duquesa mantenía con jesuitas y franciscanos, que algunos procediesen de Oriente, si tenemos en cuenta el papel que al menos los miembros de la Compañía de Jesús, tuvieron en el envío a Europa de antigüedades orientales, y que conocemos bien en el caso de la biblioteca real francesa ${ }^{24}$.

${ }^{20}$ N. Maillard Álvarez, «María Guadalupe de Lencastre, duquesa de Arcos y Aveiro, y su biblioteca», en Actas de la XIV Jornadas sobre Historia de Marchena: Iglesias y conventos (Marchena 2011) págs. 139-157. También con noticias de su biblioteca: L. de Moura Sobral, «María Guadalupe de Lencastre (1630-1714). Cuadros, libros y aficiones artísticas de una duquesa ibérica» Quintana 8 (2009) págs. 61-73.

${ }^{21}$ F. M. DE Mena, «Carta a Gregorio Mayans, 15 de octubre de 1746», en Epistolario XII. Mayans y los libreros, ed. A. Mestre (Valencia 1993) págs. 501-502.

${ }^{22}$ Ortega Monasterio, «Las bibliotecas y sus manuscritos hebreos», pág. 41.

${ }^{23}$ M. R. LAPA, ed. Amadís de Gaula (4 ${ }^{\mathrm{a}}$ ed. Lisboa 1941) pág. X.

${ }^{24}$ H. Omont, Missions archéologiques françaises en Orient au XVII et XVIII siècles (Paris 1902). 


\begin{abstract}
ANEXo
Texto de Martín Sarmiento referido a los manuscritos hebreos de San Martín de Madrid en la Obra de 660 pliegos $^{25}$ (MP, Col. Medinasidonia, t. XVII, fols. $450 \mathrm{r}-452 \mathrm{v}$ )
\end{abstract}

[fol. 450r] Mas digo. tal vez no se necesitarà saber con perfeccion, ni el idioma del contexto; ni la exactitud de los Caracteres; para rastrear algo del Secreto en general. Pondrè un exemplo. Quando el Cardenal de Aguirre venia desde Salamanca para Roma, se detuvo algun tiempo en el Monasterio de $\mathrm{S}^{\mathrm{n}}$ Martin de Madrid. Entonces se amistò con el la Exc. ${ }^{\text {ma }}$ S. ${ }^{\text {ra }}$ Duquesa ultima de Aveiro D. ${ }^{a}$ Maria de Guadalupe; que era una Doctisima y muy Erudita Señora. Esta regalò al Cardenal al despedirse, unos 18 Codices M. S. ${ }^{\text {tos }}$ Hebreos, de todas marcas; en pergamino, y de mucha antiguedad. Y el Cardenal regalò al dho. Monasterio, con los dhos. Codices ${ }^{\left[{ }^{[f o l} .450 v\right]}$ Hebreos; y estos se colocaron en un armario cerrado, que està en la Bibliotheca del dho. Monasterio, en donde actualmente se conservan.

(7091) tuve ocasion de manosear esos Codices, muy por alto, y sin entenderlos. Preguntè à uno que avia sido Cathedratico de Lenguas en Salamanca, que me dixese, que libros eran aquellos? Violos, revolviolos; y solo me respondio: Estos son Rabinos, que yo no entiendo; y asta alli estabamos iguales. Por los años de 34 tuve ocasion de poder rexistrar à mis solas, y de espacio, todos los dhos. Codices Hebreos. Estaban muy ajados, estropeados, unos desenquadernados, $\mathrm{y}$ otros enquadernados muy mal. Procurè, que todos se enquadernasen bien, y con uniformidad respectiva ${ }^{26}$. Con esa ocasion, registrè uno, por uno, y tentè aberiguar à lo menos, el nombre del Autor, y el Asunto. Algo consegui de bueno. Y en un Papel blanco que mandè poner en cada uno de los 18 Codices, escribì lo que pude averiguar; y que uno de buena Pluma, pusiese ${ }^{[\text {fol. } 451 r]}$ el rótulo en el lomo, del Autor, y de la Materia

(7092) Valime para todo, de la Bibliotheca de Buxtorfio: de la Rabinica de Bartolocio: y de la Hebrea de Wolfio, etc. Entre los dhos. Codices ay dos en $8^{\circ}$ grande, que contienen el Pentateucho Arabigo; y en Arabigo. El uno Escrito con Caracteres Hebreos quadrados. Y el otro, escrito con Caracteres Rabinicos. Por los años de 940 tradujo el Hebreo Saadias Gaon, todo el Pentateucho Hebreo, al idioma Arabigo. Y para que no lo entendiesen los Mahometanos, se escribia, ya con Caracteres Hebreos; ya con Caracteres Rabinicos. Esta versión Arabiga del Pentateucho, de Saadias Gaon, es muy celebrada por su antiguedad. $\mathrm{Y}$ asi son Alhajas muy singulares, los dos Codices dhos.; y podran ser ornamento de una Bibliotheca, ô Regia; ô Pontificia.

${ }^{25}$ En la transcripción se respetan las características ortográficas y puntuación del manuscrito.

${ }^{26}$ Conservan esta encuadernación los manuscritos de la Biblioteca Nacional (en adelante BNE) con signaturas Ms. 5454, 5467, 5470, 5475, 5476 y 5478, y no la conserva el Ms. 4188. 
(7093) Dirè el acaso por donde tropezè el saber, que el contexto era Arabigo, y [fol. 451v] los Caracteres Hebreos. Pasando los ojos, por el Codice del Pentatucho mas antiguo ${ }^{27}$, con los Caracteres quadrados, a cada paso leia repetido el Artículo Al. Al. Al. Al.; y aunque no sè Arabigo, sino tal qual voz vaga, hice evidencia que era idioma Arabigo el del contexto. Despues, tuve poco que hacer, en conocer, que el idioma del contexto del otro Codice del Pentateucho escrito con Caracteres Rabinicos, tambien era Arabigo. Ni se Arabigo: ni Rabinico; ni Hebreo. Pero no me son totalmente desconocidos, los Caracteres Hebreos, Rabinicos y Arabigos. tengo Vocabularios; Hebreo, de Santes Pagnino; talmúdico, de Buxtorfio; y Arabigo, de Golio. Y no me és muy difícil vuscar una voz suelta, en ellos.

(7094) Abrà cosa de tres años, que se apareció en Madrid un Erudito Ingles, de Casa del Embajador, que tenia Comision de M. ${ }^{\mathrm{r}}$ Kenicoth, y compañeros de Londres, de recoger por España, la noticia de todos los Codices M.S. ${ }^{\text {tos }}$ Hebreos del testamento ${ }^{\text {[fol. } 452 r]}$ viejo, que en España se conserva. Y es, que ${ }^{28}$ en Ynglaterra se piensa imprimir una immensa obra. Esta es, una Noticia universal de todos quantos Codices Hebreos M.S. ${ }^{\text {tos }}$ del testamento viejo, ay en Europa; con la colacion de muchos; y con las variaciones, travajo improvo, y costoso.

(7095) Estuvo en la Libreria de S. ${ }^{\mathrm{n}}$ Martin de Madrid, el dho. Comisionado; y alli vio los 18 Codices Hebreos; de los cuales, solo de tres sacò noticia. De los dos Pentateuchos: $\mathrm{y}$ de otro tercer Codice, que ès el mayor y mas exquisito. Este es un Codice muy grande, y en pergamino, que contiene la $2^{\text {a }}$ Parte de toda la Biblia Hebrea. Los Caracteres son quadrados, y grandes, casi como Avellanas: y con todos los Acentos y Puntos. Es lastima que no acompañe â este tomo $2^{\circ}$, el otro tomo $1^{\circ}$. Este tomo $2^{\circ}$ se debia colacionar, y observar sus varias lecciones. Pero ninguno quiso tomar ese travajo molesto. Contentose el Comisionado con Copiar lo que yo tenía ${ }^{\left[{ }^{[f o l ~ 452 v] ~}\right.}$ escrito de mi Letra, à lo ultimo de los tres Codices dhos. de la Biblia: por si acaso en algun tiempo se ofreciere alguno à colacionarlos.

(7096) Espero, que no será desagradable al Letor, esta noticia literaria de los 18 Codices Hebreos M. S. ${ }^{\text {tos }}$ de la Bibliotheca de S. ${ }^{n}$ Martin de Madrid. todo ha pasado por mis ojos, manos, y pluma. Y aunque ligera esta noticia, servirá de mucho al que fuera inteligente en estas materias. No quise dar noticia indibidual de los 15 Codices restantes. Baste, saber que son obras de los Rabinos mas doctos: Kimhi: Maimon: Nachman: Nathan: Salomon, etc. Solo he traido al caso, los dos Codices del Pentateucho; por la singularidad de estar escritos en un idioma; y con Caracteres de otro distinto. Lo mismo se debe entender de las ficciones de Miguel de Luna ...

Recibido: $27 / 12 / 2016$

Aceptado: 09/03/2017

${ }^{27}$ BNE, Ms. 5475.

${ }^{28}$ Nota marginal de distinta mano: «N. En la Gazeta de Ma. ${ }^{\text {d de }} 27$ de julio de 773, se dà noticia de aver dado ya principio el $\operatorname{Doc}^{\mathrm{r}}$ Kennicot à la edicc ${ }^{\text {on }}$ de esta Biblia por subscripcion». 